\section{Jean-Paul Lévy}

\title{
Le problème d'un vaccin contre le SIDA
}

Le virus de l'immunodéficience humaine (VIH) diffère de la plupart des autres virus car il provoque une infection chronique qui colonise le système lymphoïde, s'intègre dans le génome de l'hôte, est d'une variabilité extrême et se propage par l'intermédiaire des cellules infectées aussi bien que par des particules virales libres. Pour lutter contre cet agent prodigieusement intelligent, il faut donc inventer des processus vaccinaux nouveaux permettant une triple réponse immunitaire : production d'anticorps neutralisants, induction de cellules $\mathbf{T}$ tueuses et d'une immunité muqueuse relayée par des IgA sécrétoires anti-VIH. On dispose actuellement, avec les recombinants viraux (voire bactériens), les protéines recombinantes purifiées, les peptides et lipopeptides de synthèse, et peut-être bientôt avec l'ADN lui-même, d'une série d'outils vaccinaux dont l'utilisation, en diverses associations, pourrait être efficace. Mais nous sommes encore loin de la mise au point d'un vaccin contre le SIDA.

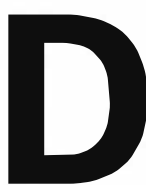
epuis que le lien a été établi entre le VIH-1 et le SIDA, l'annonce d'un vaccin disponible pour le proche futur a été faite à maintes reprises, avec une notable imprudence. Elle repose sur l'idée trop simple que lorsqu'un agent infectieux est isolé, sa production en quantité suffisante, sous une forme non pathogène mais susceptible d'entraîner une protection chez l'être humain, n'est qu'une question d'application technique.

\section{Le VIH-1 est très différent des virus contre lesquels une vaccination existe}

En vérité, le problème posé par un vaccin anti-VIH-1 est tout à fait nouveau et ne bénéficie que partiellement des expériences antérieures.
Pour la première fois, il s'agit de protéger contre un rétrovirus qui, par de multiples caractères, est très différent de la douzaine de virus contre lesquels une vaccination est pratiquée chez l'homme (figure 1). Les principales différences, sur lesquelles on insiste curieusement très peu, sont les suivantes:

1. Ces virus induisent habituellement des maladies aiguës, qui peuvent tuer mais guérissent dans la majorité des cas, en quelques jours à quelques semaines. Le VIH provoque, au contraire, une infection chronique dont les conséquences n'apparaissent qu'au bout de dix ans en moyenne.

2. Pour toutes les maladies contre lesquelles nous savons vacciner, l'organisme démontre une capacité spontanée de contrôler l'inf ection naturelle grâce à la réaction immunitaire. C'est une course de vitesse entre celle-ci et
J.P. Lévy: professeur, directeur de l'ANRS 75014 Paris, France. 
Tableau 1

PARTICULARITÉS DES VIH PAR RAPPORT AUX VIRUS POUR LESOUELS DES VACCINATIONS EXISTENT

\begin{tabular}{|c|c|c|}
\hline Propriétés du virus & $\begin{array}{l}\text { Virus faisant l'objet } \\
\text { de vaccination }\end{array}$ & VIH \\
\hline Type d'infection & Aiguë, résolutive & Chronique \\
\hline $\begin{array}{l}\text { Contrôle de l'infection } \\
\text { par la réponse immuni- } \\
\text { taire }\end{array}$ & $\begin{array}{l}\text { Habituel ou facilement } \\
\text { inductible (rage) }\end{array}$ & $\begin{array}{l}\text { Exceptionnel, s'il } \\
\text { existe }\end{array}$ \\
\hline $\begin{array}{l}\text { Cellules cibles princi- } \\
\text { pales ou primitives }\end{array}$ & $\begin{array}{l}\text { Habituellement extra- } \\
\text { lymphoïdes }\end{array}$ & $\begin{array}{l}\text { Lymphocytes CD4, } \\
\text { macrophages }\end{array}$ \\
\hline $\begin{array}{l}\text { Intégration dans le gé- } \\
\text { nome }\end{array}$ & Nulle ou marginale & Constante \\
\hline Variabilité & $\begin{array}{l}\text { Très faible pour la plu- } \\
\text { part des virus (excep- } \\
\text { tion: la grippe) }\end{array}$ & Considérable \\
\hline Modalités de l'infection & Par particules virales & $\begin{array}{l}\text { Par particules et par } \\
\text { cellules infectées }\end{array}$ \\
\hline Vaccins vivants ou tués & $\begin{array}{l}\text { De pratique courante } \\
\text { (exception: I'hépatite B) }\end{array}$ & En principe exclus \\
\hline
\end{tabular}

1. Ulmer JB, Donnelly JJ, Parker E, et al. Heterologous protection against influenza by injection of DNA encoding a viral protein. Science 1993 ; 259 : 1745-9.

2. Wang B, Ugen KE, Srikantan V, et al. Gene inoculation generates immune responses against human immunodeficiency virus type 1. Proc Natl Acad Sci USA 1993; 90 : 4156-60.

3. Fynan EF, Webster RG, Fuller DH, et al. DNA vaccines protective immunizations by parenteral, mucosal and gene-gun inoculations. Proc Natl Acad Sci USA 1993; 90: 11478-82.

4. Brand D, Truong C, Barin F. Domaines fonctionnels de l'enveloppe du VIH-1 et anticorps neutralisants. medecine/sciences 1994 ; 10: 417-24.

5. Girard M, Kieny MP, Pinter A, et al. Immunization of chimpanzees confers protection against challenge with human immunodeficiency virus. Proc Natl Acad Sci USA $1991 ; 88: 542-6$.

6. Berman PW, Gregory TJ, Riddle L, et al. Protection of chimpanzees from infection by HIV-1 after vaccination with recombinant glycoprotein gp120 but not gp160. $\mathrm{Na}$ ture $1990 ; 345$ : $622-5$.

7. Fultz PN, Nara P, Barre-Sinoussi F, et al. Protection of chimpanzees against challenge with HIV-1 infected peripheral blood mononuclear cells. Science 1992 ; 256 : 168790 .

8. Martinon F, Gras-Masse $\mathrm{H}$, Boutillon $\mathrm{C}$, et al. Immunization of mice with lipopeptides bypasses the prerequisite for adjuvant. $/ \mathrm{Im}$ munol 1992; 149: 3416-22.

9. Bourgault I, Chirat F, Tartar A, et al. Simian immunodeficiency virus as a model for vaccination against HIV: induction in rhesus macaques of GAG- or NEF- specific cytotoxic T lymphocytes by lipopeptides. $J$

\begin{tabular}{|c|}
\hline $\begin{array}{c}\text { Tableau ॥ } \\
\text { COMPOSANTS VACCINAUX SUSCEPTIBLES D'INDUIRE } \\
\text { UNE IMMUNITÉ ANTI-VIH-1 }\end{array}$ \\
\hline $\begin{array}{l}\text { 1. Composants protéiques du virus } \\
\text { - Protéines virales recombinantes } \\
\text { - Peptides ou lipopeptides de synthèse } \\
\text { 2. Vecteurs recombinants vivants exprimant des protéines du VIH } \\
\text { - Vecteurs viraux } \\
\text { - Vecteurs bactériens } \\
\text { 3. Pseudoparticules virales } \\
\text { 4. Gènes viraux sous formes d'ADN } \\
\text { 5. Vaccins idiotypiques }\end{array}$ \\
\hline
\end{tabular}

la multiplication virale qui conditionne pour l'essentiel le pronostic immédiat. Le système immunitaire échoue au contraire à contrôler l'infection par le VIH, au moins dans la grande majorité des cas. Il n'est pas exclu qu'un certain nombre de sujets puissent être infectés et contrôler cette infection, mais les stigmates immunitaires qui en résultent seraient alors très inhabituels, sans séroconversion, ce qui suggère un phénomène différent de la guérison habituelle des inf ections virales (figure 1).

3 . Nous vaccinons contre des infections au cours desquelles le virus ne colonise pas le système lymphoïde ou, s'il le fait, ne le colonise que se- condairement, les cibles primaires et celles de la maladie développée étant habituellement de nature différente. Le VIH colonise initialement, puis tout au long de l'infection, les lymphocytes CD4, les macrophages, voire les cellules dendritiques. En outre, il inf ecte très précocement le système nerveux central, dans lequel il est probablement susceptible de persister de façon prolongée, pour l'essentiel à l'abri de la réponse immunitaire.

4. Contrairement au VIH, qui s'intègre définitivement dans le génome des cellules hôtes et peut y rester muet de façon prolongée, l'intégration génétique manque complète- 


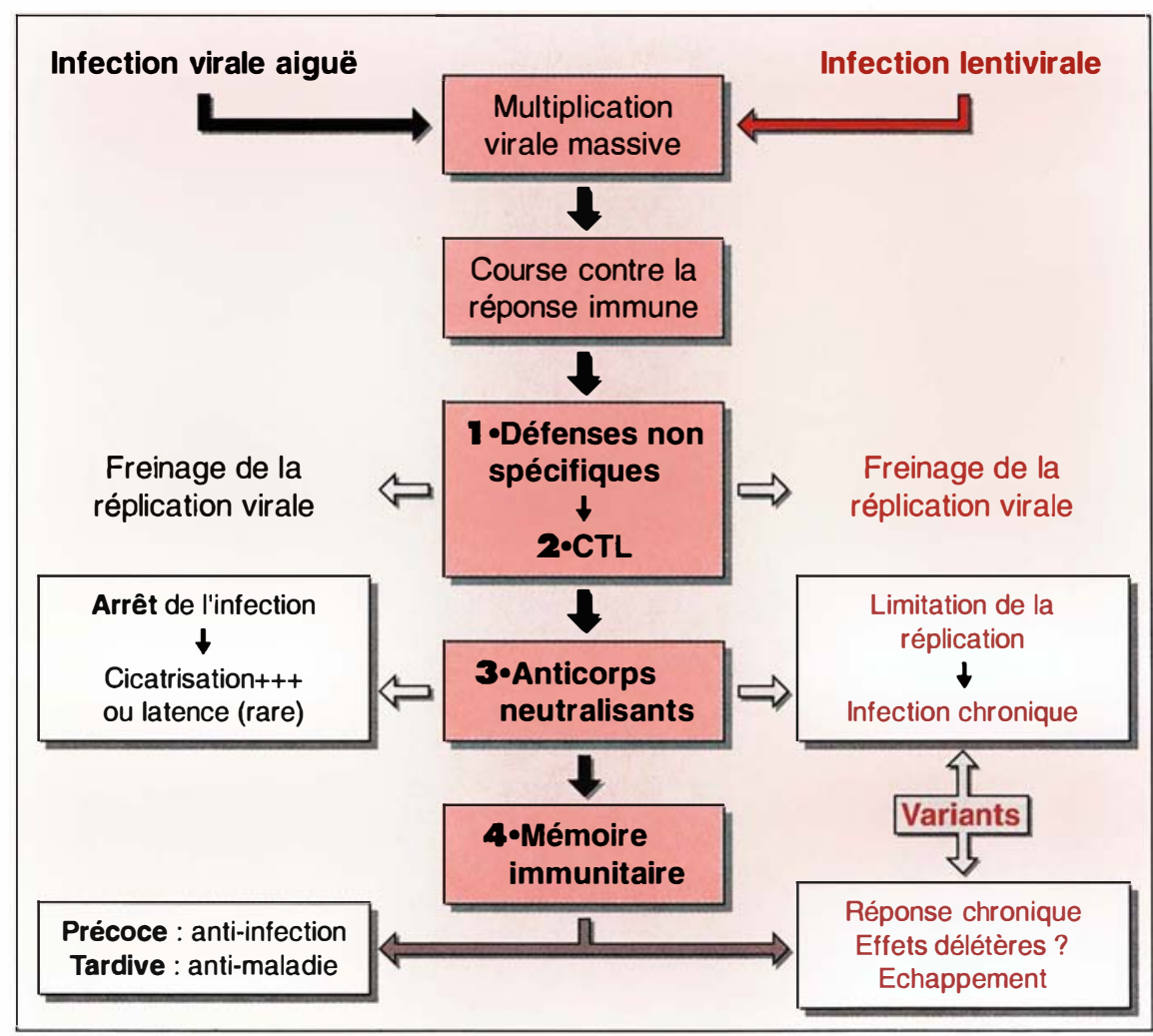

Figure 1. Réactions immunitaires dans les infections lentivirales et dans les autres infections virales aiguës.

ment ou ne survient que de façon accessoire dans le cas des virus contre lesquels nous savons vacciner.

5. La variabilité spontanée du virus VIH est sans commune mesure avec celle que l'on observe pour tous ces virus. Le seul qui s'en rapproche, sans atteindre, et de beaucoup, le même degré de variabilité, est l'influenza $\mathrm{A}$, et l'on sait les problèmes que pose à cet égard la vaccination antigrippale.

6. L'infection est transmise habituellement par du virus libre alors que, dans le cas du VIH, elle l'est de façon probablement prioritaire par des cellules infectées.

7. Enfin, et ce n'est pas le moindre problème, tous les vaccins antiviraux, $m / s n^{\circ} 3$, vol. 11 , mars 95 myélite, hépatite A, rage) ou grâce à des vaccins vivants atténués (variole, adénovirus, rougeole, oreillons, poliomyélite, rubéole, varicelle, fièvre jaune). Les caractéristiques propres du VIH rendent peu probable l'utilisation de vaccins vivants (Tableau 1) en raison de l'intégration du virus dans le génome cellulaire et de la production virale chronique qui en résulterait. De l'intégration, on pourrait craindre l'activation d'oncogènes, voire la recombinaison avec des séquences rétrovirales endogènes qui sont nombreuses chez l'homme. De la production virale chronique, on pourrait redouter l'apparition ultérieure de maladies imprévisibles, notamment de lymphomes, après de nombreuses années, voire des décennies. La certitude de l'innocuité serait donc très difficile à obtenir pour ces vaccins vivants. On peut se demander, en outre, quels seraient les risques de diffusion du virus vaccinant dans les populations humaines. De la même façon, la mise au point de vaccins tués paraît actuellement improbable, parce qu'il est difficile de s'assurer de l'inactivation complète d'un rétrovirus (en théorie la persistance de quelques molécules actives de transcriptase inverse et de rares génomes viraux pourrait suffire à provoquer l'infection), mais aussi parce qu'il est difficile pour le moment de produire le virus en quantités massives, ce qui rendrait la diffusion d'un vaccin de ce type incertaine et coûteuse. En outre, les expériences qui ont été menées dans ce domaine sur des modèles animaux n'ont pas apporté de protection spécifique significative. Toute la recherche vaccinale s'est donc orientée sur des approches plus sophistiquées (mais plus aléatoires si on se réfère à l'expérience des vaccinations antérieures), basées sur l'apport de protéines virales, qui ne comporte évidemment aucun risque d'infection ou d'intégration.

On ne développera pas ici la cinquième approche indiquée dans le $T a$ bleau II, qui a recours au réseau idiotypique, c'est-à-dire à l'utilisation d'un anticorps ab2 (anti-anti-protéine virale). Un tel anticorps est susceptible, en principe, de remplacer un antigène et d'être produit en quantité abondante $\left(m / s n^{\circ} 2, v o l\right.$. 4 , p. 130). Cependant, les données jus- 


\section{RÉFÉRENCES}

10. Layton GT, Harris SJ, Gearing AJH, et al. Induction of HIV-specific cytotoxic T lymphocytes in vivo with hybrid HIV-1 V3: Ty virus-like particles. I Immunol 1993; 151 : rus-like part-107.

11. Martin SJ, Viakarnam A, Cheinsong-Popov $\mathrm{R}$, et al. Immunization of human HIVseronegative volunteers with recombinant $\mathrm{p} 17 / \mathrm{p} 24$ : Ty virus-like particles elicits HIV-1 p24-specific cellular and humoral immune responses. AIDS 1993; 7: 1315-23.

12. Rovinski B, Haynes JR, Shi Xian Cao, et al. Expression and characterization of genetically engineered human immunodeficiency virus like particles containing modified envelope glycoproteins: amplification for developpement of a cross-protective vaccine. J Virol 1992; 66: 4003-12.

13. Emini EA, Schleif WA, Numberg JH, et al. Prevention of HIV-1 infection in chimpanzees by gp120 V3 domain-specific monoclonal antibody. Nature 1992; 355 : 728-30.

14. Mascola JR, Louwagie J, McCutchan FE, et al. Two antigenically distinct subtypes of human immunodeficiency virus type $\mathrm{I}$ : viral genotype predicts neutralization serotype. $J$ Infect Dis 1994; 169: 48-54

15. Klenerman P, Rowland-Jones S, McAdam $S$, et al. Cytotoxic T-cell activity antagonized by naturally occuring HIV-1 gag variants. Nature 1994; 369: 403-10.

16. Couillin I, Culmann-Penciolelli B, Gomard $\mathrm{E}$, et al. Impaired CTL recognition due to genetic variations in the main immunogenic region of the HIV-1 nef protein. $J$ Exp Med 1994 (sous presse).

17. Kang CY, Hariharan K, Nara PL, et al. Immunisation with a soluble CD4-gp120 complex preferentially induces neutralizing anti-human immunodeficiency virus type I antibodies directed to conformation-dependant epitopes of gpl20. J Virol $1994 ; 68$ : qu'ici obtenues dans ce domaine sont peu convaincantes, d'autant moins que la variabilité virale limite cette approche et que nous savons par ailleurs qu'il faudra vraisemblablement immuniser contre plusieurs protéines virales simultanément pour une vaccination efficace. Des études fondamentales se poursuivent cependant, dont les résultats seraient intéressants seulement si l'on arrivait à obtenir des ab2 fortement immunogènes qui soient les images de structures virales conservées et cibles d'anticorps neutralisants. Toutefois, même dans ce cas, il y a peu de chances que cet unique composant puisse constituer à lui seul un vaccin L'approche prometteuse par l'ADN viral en est, de son côté, à ses débuts. Le principe est d'utiliser une fraction du génome viral pour induire une immunisation contre les protéines d'enveloppe et contre une partie des protéines internes. Les données obtenues dans d'autres systèmes suggèrent qu'il est possible par injection d'ADN nu dans les cellules musculaires d'obtenir une expression prolongée de l'antigène et, par conséquent, une immunisation importante avec de bonnes réponses par anticorps, mais aussi le développement de cellules $\mathrm{T}$ tueuses, puisque l'antigène est présenté par des cellules vivantes [1-3]. Des incertitudes persistent cependant sur l'innocuité de cette approche qui reste expérimentale.

Les vecteurs viraux recombinants aujourd'hui envisagés sont très nombreux. Des virus pox, des adénovirus, celui de la poliomyélite et celui de l'hépatite $B$ ont été particulièrement étudiés et d'autres virus seraient envisageables (herpès, influenza, mingovirus). Chez l'homme, seuls les pox ont déjà donné lieu à des essais, à partir de recombinants de souches vaccinales atténuées, ou à partir d'un virus aviaire, le canarypox (la vaccine du canari), qui a l'avantage de n'exprimer dans les cellules de mammifères que ses gènes précoces, et de n'induire par conséquent aucun effet délétère sur les cellules humaines. On obtient habituellement, en immunisant avec ces recombinants viraux, une réponse significative par les cellules $\mathrm{T}$ tueuses, mais peu d'anticorps anti-VIH et a fortiori peu d'anticorps neutralisants. Cela est peut- être dû à la quantité d'antigène nécessaire pour induire ce type de réponse. Cependant, il est clair, après les essais récemment réalisés avec un canarypox en France, que les lymphocytes $\mathrm{T} \mathrm{CD}^{+}$sont efficacement stimulés in vivo et susceptibles de favoriser une réponse anticorps importante lors d'une stimulation ultérieure par une protéine. Cela suggère que les recombinants vivants devraient être utilisés dans des vaccins mixtes les associant à des protéines purifiées ou des peptides. Par ailleurs, à côté de vecteurs n'exprimant que le gène $E N V$ du VIH-1, il est essentiel de tester des vecteurs exprimant simultanément d'autres protéines. On peut en attendre une réponse CTL plus large grâce aux protéines internes qui sont de meilleures cibles de CTL, une meilleure stimulation des cellules $\mathrm{CD} 4$, et donc de la réponse anticorps. C'est ce qu'a entrepris de tester en France l'essai ANRS/VAC03 (Pasteur Mérieux Sérums et Vaccins) avec un canarypox vCP 205 qui exprime ENV, GAG et une partie du gène POL du VIH-1. Enfin, la recherche se poursuit de vecteurs viraux utilisables par voie orale et susceptibles de déclencher une immunité muqueuse (par exemple, adénovirus ou poliovirus). Un problème reste cependant posé pour tous les vecteurs viraux recombinants (aussi bien que pour les vecteurs bactériens, d'ailleurs) : ils induisent une réponse immunitaire contre le vecteur lui-même et on peut se demander s'il sera possible de restimuler la réponse immunitaire anti-VIH-1 lors de vaccinations ultérieures car, si l'on a recours au même recombinant, il risque d'être rapidement éliminé. Cela peut compromettre à l'avenir l'utilisation de ces vecteurs si une mémoire immunitaire très puissante n'est pas induite dès les premières stimulations.

En ce qui concerne les recombinants bactériens, qui sont surtout des recombinants utilisables par voie orale pour stimuler une immunité muqueuse, les études sont aujourd'hui beaucoup moins avancées. Le BCG exprimant un certain nombre de protéines virales pourrait être intéressant mais on étudie aussi des vecteurs salmonelles, shigelles, ou des bacilles lactiques. On sait peu de choses actuellement sur l'immunité 


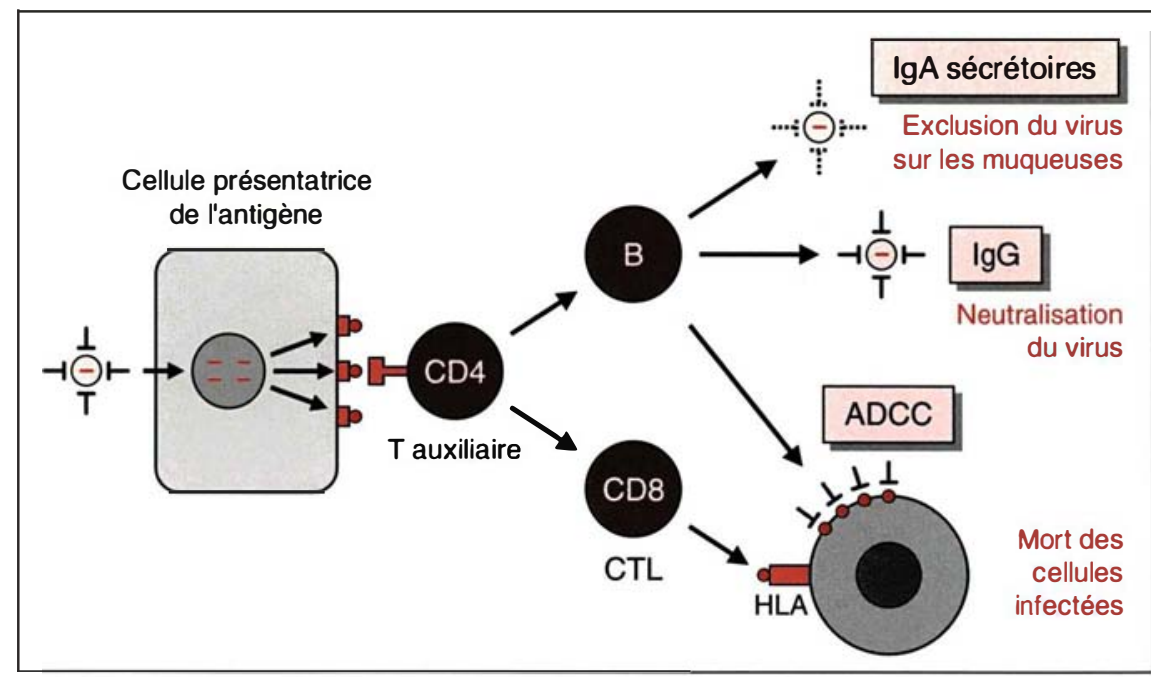

Figure 2. Triple réponse immune antivirale. Par la vaccination, on cherche à induire une triple réponse immune antivirale : production d'anticorps neutralisant le virus (lgG), production d'lgA sécrétoires susceptibles d'induire l'exclusion du virus sur les muqueuses, production de cellules $T$ tueuses (CTL) capables de tuer les premières cellules infectées (le rôle des anticorps dans le phénomène voisin de l'ADCC [antibody-dependent cellular cytotoxicity] est moins bien établi).

induite par ces vecteurs bactériens et, en particulier, ce qu'ils sont susceptibles d'apporter sur l'immunité muqueuse, d'une part, et en terme de réponses CTL ou anticorps neutralisants, d'autre part. Citons par ailleurs l'utilisation de la sous-unité B de la toxine cholérique (CTB) comme vecteur possible d'antigènes recombinés avec cette sous-unité dont on sait qu'elle induit une forte réponse IgA sécrétoire.

La plus grande partie des expériences qui ont été réalisées jusqu'à maintenant chez l'homme, et même sur les modèles expérimentaux, ont été principalement menées à l'aide "de vaccins anti-sous-unités" constitués de protéines virales. Pour l'essentiel, ce sont les protéines d'enveloppe du VIH-I, la GP120 ou la GP160, qui ont été utilisées seules [4]. Cependant, dans un certain nombre d'expériences on a eu recours également à des peptides de synthèse qui portaient la séquence de la cible principale des anticorps neutralisants naturels (la boucle V3), seule ou associée à d'autres séquences susceptibles de constituer des épitopes stimulants pour les lymphocytes CD4. Il est clair que l'on peut obtenir à l'aide de protéines et, mieux encore, de combinaisons protéines + peptides, une répon$\mathrm{m} / \mathrm{s} n^{\circ} 3$, vol. 11 , mars 95 ticorps neutralisants à l'aide de lipopeptides de synthèse $[8,9]$. Ceux-ci auraient donc l'avantage de permettre la stimulation des diverses réponses immunitaires en ayant recours à un seul type de préparation, ce qui éviterait d'associer des recombinants vivants et des préparations protéiques ou peptidiques en un vaccin complexe. Un autre avantage des lipopeptides est qu'ils seraient susceptibles d'emploi répété à long terme, puisqu'ils ne déclenchent pas, en eux-mêmes, de réactions immunitaires spécifiques du vecteur, comme le font les recombinants vivants. Un essai chez l'homme est en cours de préparation (ANRS VAC/04).

Enfin, une autre possibilité d'apport de protéines virales est l'utilisation de pseudoparticules virales. Les particules Ty, venant d'un transposon de levure et exprimant la protéine p24 $[10,11]$, ont été administrées à l'homme et peuvent induire, semblet-il, des réponses CTL et anticorps. Des pseudovirions VIH dépourvus de génome et produits par génie génétique devraient, de leur côté, entrer bientôt en expérimentation [12].

Au total, nous disposons actuellement avec les recombinants viraux (voire bactériens), les protéines recombinantes purifiées, les peptides et lipopeptides de synthèse, et peut-être bientôt avec l'ADN, d'une série de vecteurs dont l'utilisation selon diverses associations devrait nous permettre d'induire des réponses immunitaires diversifiées (figure 2). multimérique. Il est clair surtout que la réponse $T$ tueuse n'est pratiquement pas stimulée par les protéines ou les peptides, et cela n'est pas surprenant compte tenu de ce que l'on connaît pour d'autres virus. C'est pourquoi on teste actuellement (ANRS/VACO3) une association canarypox VCP205 + peptides. Le peptide est en outre, dans ce cas, une structure associant un épitope de V3 (cible d'anticorps neutralisants) et un épitope de GAG stimulant les cellules CD4.

La manipulation des peptides pour y introduire non seulement des épitopes stimulant les cellules CD4, mais encore un composant lipidique pourrait peut-être améliorer ces approches. On a vu sur des modèles expérimentaux murins et simiens qu'il était possible d'induire à la fois de bonnes réponses $\mathrm{T}$ tueuses et des an-

\section{On cherche à induire une triple réponse immunitaire}

Il est remarquable de constater que les mécanismes immunologiques intervenant dans la protection des sujets vaccinés sont très mal connus (figure 2). Dans la plupart des vaccinations, on sait seulement qu'il existe une corrélation entre cette protection et l'existence d'anticorps neutralisants qui, en règle, réagissent avec une protéine de la surface du virus et empêchent son interaction avec la cellule cible (figure 3$)$. On sait très peu de chose du rôle des cellules $T$ tueuses (CTL) car, jusqu'à une date très récente, ces cellules n'avaient pas été étudiées en pratique clinique chez l'homme. On ignore également 


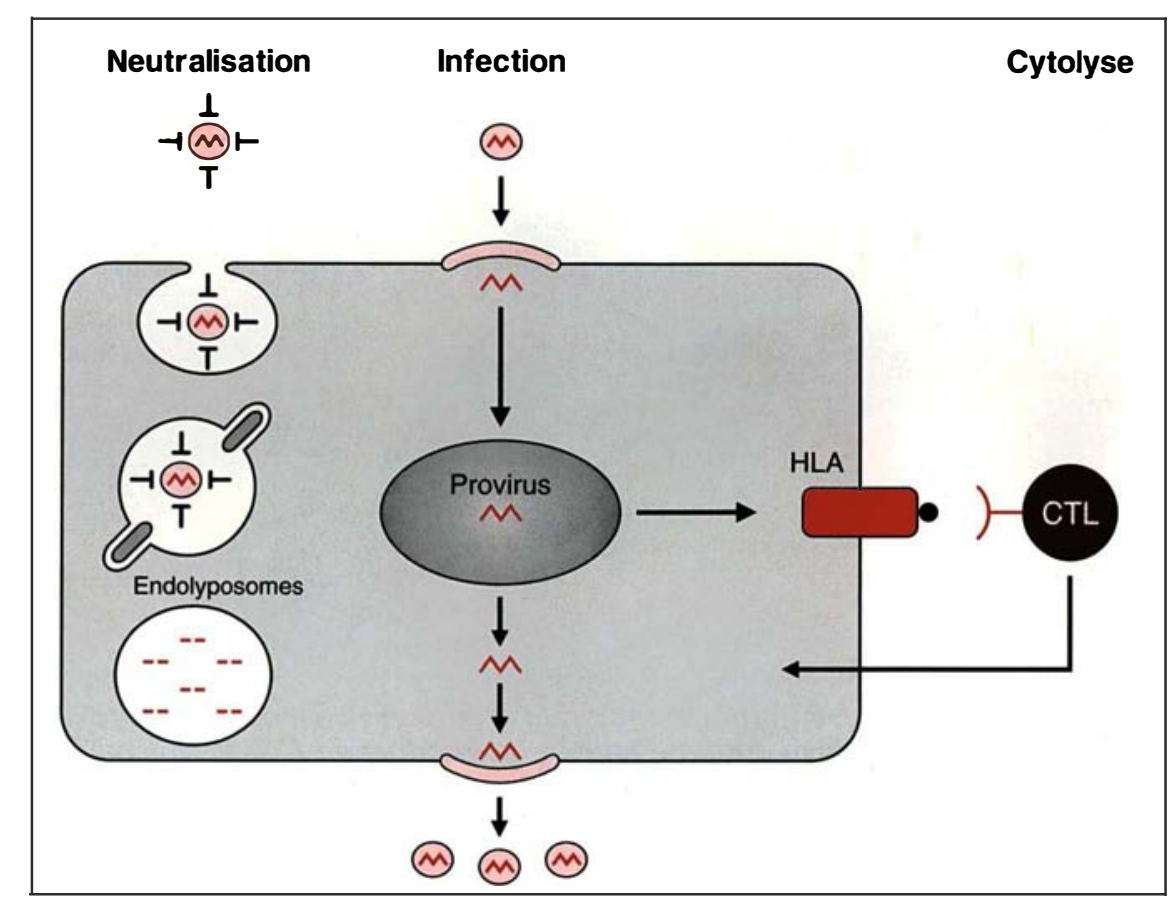

\section{RÉFÉRENCES}

18. Chan WL, Rodgers A, Hancock RD, et al. Protection in simian immunodeficiency virus-vaccinated monkeys correlates with anti-HLA class I antibody response. $J$ Exp Med 1992; 176: 1203-7.

19. Stahl-Henning C, Voss G, Dittmer U, et al. Protection of monkeys by a split vaccine against SIV $_{\mathrm{mac}}$ depends upon biological properties of the challenge virus. $A I D S 1993 ; 7$. 787-95.

20. Cranage MP, Polyanskaya N, McBride B, Cook N, et al. Studies on the specificity of the vaccine effects elicited by inactivated simian immunodeficiency virus. Aids Res Hum Retro 1993; 9: 13-22.

21. Schols D, Pauwels R, Desmyter I, et al. Presence of class II histocompatibility DR proteins on the envelope of human immunodeficiency virus demonstrated by FACS analysis. J Virol 1992; 189: 374-6.

22. Arthur LO, Bess JW Jr, Sowder II RC, et $a l$. Cellular proteins bound to immunodeficiency viruses: implications for pathogenesis and vaccines. Science $1992 ; 258$ : 1935-8.

23. Daniel MD, Kirchhoff F, Czajak SC, et al. Protective effects of a live attenuated SIV vaccine with a deletion in the Nef gene. Science 1992 ; 258 : 1938-41.

24. Blower SM, McLean AR. Prophylactic vaccines, risk behavior change, and the probability of eradicating HIV in San Francisco. Science 1994; 265 : 1451-4.

25. Girard M. Vaccins contre le SIDA: espoirs et réalitês. médecine/sciences $1989 ; 5$ :
Figure 3. Complémentarité des réponses immunes par anticorps neutralisants et cellules $T$ tueuses (CTL). L'infection entraîne l'intégration virale dans le génome, puis la production de nouveaux virions (au centre). La neutralisation est la méthode idéale de protection, car elle entraîne l'incorporation du virus et sa destruction dans les lysosomes avant intégration (à gauche). Des épitopes antigéniques viraux, présentés par une molécule HLA, sont la cible de lymphocytes cytotoxiques (CTL); il s'agit d'un mécanisme d'urgence qui "fait la part du feu" en tuant ces cellules qui ont déjà intégré le virus (à droite). La production virale se fait par le bourgeonnement, emportant un fragment de membrane cellulaire (en bas).

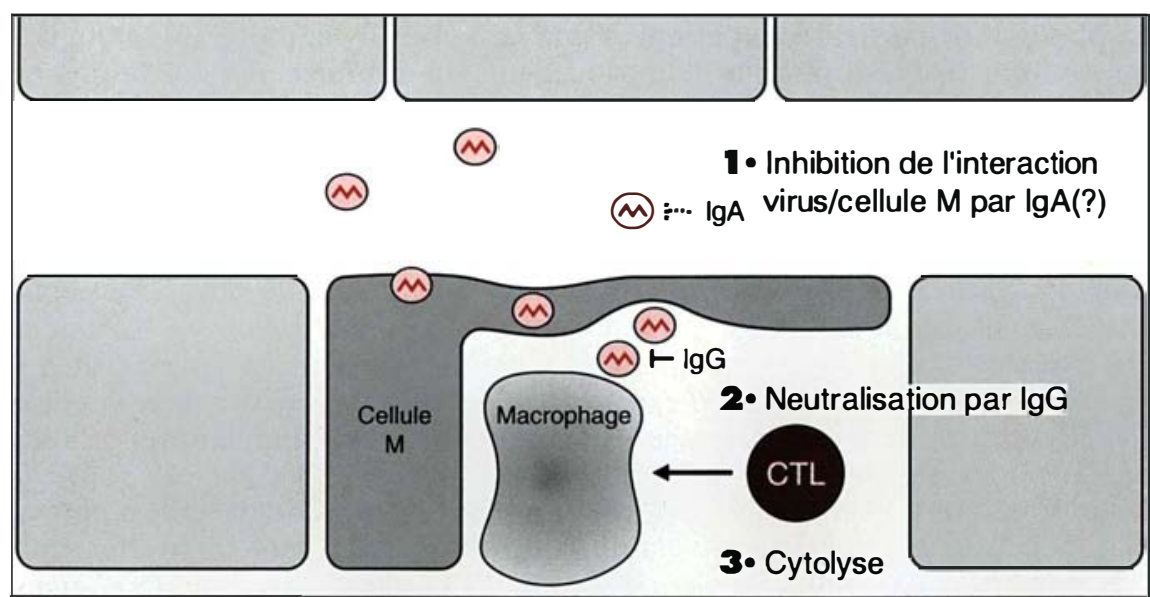

Figure 4. Immunité muqueuse. L'immunisation avec production d'IgA sécrétoires au niveau de la muqueuse pourrait empêcher l'interaction entre virus et cellules $M$, ce qui inhiberait la transcytose du virus à travers les cellules $M$ et le transport du virus vers ses cibles, macrophages et cellules T. Passée cette barrière, les anticorps neutralisants et les cellules tueuses sont nécessaires pour arrêter l'infection. 
à peu près tout du rôle d'une immunité muqueuse liée à des IgA sécrétoires. Dans le cas de l'infection par les VIH, les seuls éléments d'information dont nous disposons aujourd'hui suggèrent que les anticorps neutralisants ont un possible effet protecteur, au moins transitoire. Cela a été montré par immunisation passive chez le chimpanzé [13], à condition d'injecter l'anticorps avant le virus ou dans les minutes qui suivent son inoculation; il existe par ailleurs une corrélation assez suggestive entre l'apparition d'anticorps neutralisants et la protection des chimpanzés par des vaccins constitués de protéines ou d'association protéines/peptides V3 [5, 7]. L'un des buts essentiels de la recherche actuelle est donc d'induire, chez l'homme, des anticorps neutralisants à titre relativement élevé. C'est ce que l'on a observé, mais à court terme, dans un certain nombre d'essais ayant recours à des protéines et/ou à des peptides de synthèse, essentiellement lorsque les protéines recombinantes étaient produites par des cellules de mammifères. Toutefois, dans certains modèles animaux, en particulier chez les macaques vaccinés contre le VIH-2 et apparemment protégés, une corrélation nette n'a pas été établie jusqu'à présent avec les anticorps neutralisants. Récemment, il a été observé en outre (M. Girard, non publié) que des chimpanzés vaccinés contre la souche MN de VIH-1 étaient également protégés contre un virus proche, SF2, alors que les sérums de ces chimpanzés neutralisaient $\mathrm{MN}$ mais non SF2. Il n'est pas exclu en fait que la sensibilité des méthodes de neutralisation in vitro soit en cause.

Il est peu vraisemblable, cependant, qu'une protection solide et à long terme puisse être obtenue seulement par des anticorps neutralisants et, bien que cela ne soit pas démontré, on pense généralement nécessaire d'obtenir également une réponse CTL, voire une immunité muqueuse anti-virale. Il est logique de penser que les cellules $\mathrm{T}$ tueuses sont essentielles pour éliminer les premières cellules infectées car on sait que le virus passant à travers les muqueuses parvient en quelques minutes à ses cellules cibles $\mathrm{CD}^{+}$(figure 3). Il en est ainsi dans le rectum où le virus a accès aux formations lymphoïdes immédiatement sous-jacentes aux cellules $\mathrm{M}$ dont la fonction est, précisément, d'assurer la transcytose des particules intra-intestinales. Dans le vagin, qui ne comporte pas de cellules $M$, des cellules de type Langerhans affleurent à la surface des muqueuses et sont capables de transporter très rapidement le virus aux ganglions. Le VIH pouvant se repliquer dans les cellules infectées, puis passer de cellule à cellule et être transporté à distance par les lymphocytes et par les macrophages, il est peu probable que l'anticorps neutralisant seul vienne à bout de cette infection.

L'induction de CTL anti-VIH chez les vaccinés est observée lorsque l'on utilise des recombinants vivants, bien que jusqu'ici à des taux modestes. Chez le chimpanzé, elle n'a jamais été obtenue de façon significative dans les expériences de protection mais celles-ci étaient réalisées avec des vaccins protéiques ou peptidiques également inefficaces à cet égard chez l'homme. Peut-être y a-t-il là un lien avec le fait que les protections ne semblent pas persister à long terme. A l'inverse, notamment dans le cas du SIV, l'induction de CTL ne semble pas suffire à induire une protection [8]. Il est probable que, comme pour les anticorps neutralisants l'importance quantitative de la réponse obtenue est un facteur déterminant et, à cet égard, il faut noter que les expériences qui ont été menées chez l'homme, l'ont été jusqu'à présent avec des vecteurs permettant l'expression de la protéine ENV seule, alors que, selon toute vraisemblance, il faudrait obtenir une immunisation contre des épitopes de protéines internes (GAG, POL), voire de protéines régulatrices (NEF), qui sont des cibles préférentielles des CTL à la surface des cellules infectées. C'est ce que l'on tente de mettre en évidence dans des expériences en cours, en France par exemple (figure 3).

L'immunité au niveau de la muqueuse, de son côté, est susceptible d'apporter un plus à la protection immunitaire, empêchant l'accès des particules virales à leurs cibles sous les muqueuses. Elle pourrait notamment empêcher la transcytose du virus à travers les cellules M (figure 4).
Il semble donc légitime de chercher à induire des $\operatorname{Ig} \mathrm{A}$ sécrétoires anti-VIH mais nous connaissons mal l'immunité muqueuse spontanée de l'infection VIH et, plus mal encore, les moyens d'induire, dans quelque système que ce soit, une immunité puissante et persistante au niveau de la muqueuse. De nombreuses approches sont actuellement à l'étude, soit avec des recombinants bactériens (BCG, bacille lactique, etc.), soit avec des recombinants viraux (adénovirus, canarypox), soit avec la CTB combinée à des protéines de l'enveloppe virale, soit encore avec ces mêmes protéines présentées par divers substrats inertes. Nous ignorons aujourd'hui si une induction par voie générale est nécessaire pour induire une bonne immunité muqueuse et si nous avons des chances d'être efficaces selon que l'antigène est apporté par voie buccale, nasale, intestinale, rectale ou vaginale, par exemple.

Au total, notre ignorance est considérable sur le rôle respectif des diverses immunités et, bien que des théories aient suggéré récemment qu'une immunité de type TH1 menant à une réponse cellulaire prédominante plutôt que de type TH2 engendrant une réponse anticorps pourrait être bénéfique, aucun élément précis d'information n'existe. Rappelons qu'une réponse seulement relayée par des CTL ne semble pas protectrice, ce qui n'est guère en faveur de cette hypothèse. En tout état de cause, il parait aujourd'hui légitime de chercher à induire une triple immunité.

\section{Problème de l'infection par cellules}

Contrairement à la plupart des autres virus, le VIH se transmet non pas seulement par des particules virales libres mais, et probablement de façon prépondérante, par des cellules infectées, qui expriment secondairement le virus dans l'organisme du receveur. Elles sont présentes par exemple dans le sperme. Cela pose un problème car ces cellules, en principe et contrairement aux particules virales, ne sont pas accessibles aux anticorps neutralisants, notamment si elles n'expriment pas le virus au moment de l'infection. On peut penser que c'est une raison additionnelle pour que des anticorps neutralisants 
seuls ne puissent suffire à protéger. Il faut noter, cependant, que, dans certaines expériences réalisées chez les chimpanzés, une protection a été observée, non seulement contre le virus libre, mais aussi contre des cellules lymphoïdes de chimpanzés infectés [6]. En fait, nous savons très mal ce qui se passe dans l'organisme au moment de l'arrivée de ces cellules. Selon toute vraisemblance, la stimulation allogénique par les antigènes de l'hôte devrait entraîner leur activation et, rapidement, la production virale. Mais ces cellules étrangères ne sont pas accessibles aux lymphocytes $\mathrm{T}$ tueurs antiviraux de l'hôte en raison de la restriction HLA (sauf en cas de compatibilité HIA totale ou partielle). En revanche, elles devraient être accessibles à un rejet par les CTL anti-HI_A, car l'hôte développe forcément contre elles une réaction immunitaire dans les jours suivant l'infection. Ce rejet n'est cependant apparemment pas assez rapide dans les conditions naturelles pour empêcher la propagation du virus.

\section{Le problème crucial de la mémoire}

Rappelons d'abord que dans les vaccinations traditionnelles, le sujet vacciné n'est pas complètement protégé contre le virus mais qu'il l'est contre la maladie. En fait, si dans les premières semaines après la vaccination, le virus peut être éliminé dès son arrivée dans l'organisme par la réponse neutralisante, et peut-être par les CTL, très vite le taux des effecteurs diminue en dessous du seuil d'efficacité. C'est le nouveau contact avec le virus qui déclenche une réaction anamnestique puissante préparée par la vaccination antérieure (figure 5). Il y a infection mais le virus est éliminé avant que la maladie ait le temps d'apparaître (figure 5). Il faut noter en outre que ces réinfections naturelles sont, en elles-mêmes, un puissant stimulant de la mémoire immunitaire, améliorant progressivement la protection contre les infections ultérieures. On peut se demander si le problème de la vaccination contre le VIH n'est pas, d'abord, un problème de mémoire immunitaire? On sait que, s'il est possible d'obtenir une protection contre ce virus, chez des être liée à une immunité de type stérilisante. L'infection expérimentale, qui est réalisée en règle au pic de la réponse immunitaire, ou très peu après elle, à un moment où il existe un taux élevé d'anticorps neutralisants, est inefficace mais, fait remarquable, il n'existe pas de stigmates immunologiques de réinfection, comme on en voit normalement lors de l'infection d'un sujet vacciné contre un autre virus. On n'observe aucun rebond des taux d'anticorps qui témoignerait du fait que l'organisme a "vu" du virus infectieux Une telle protection, vraisemblablement assurée par les anticorps neutralisants tant qu'ils sont à un taux très élevé, ne peut persister que pendant très peu de temps et nous ne savons pas maintenir ce type de réponse à un taux suffisant pendant des périodes qui dépassent quelques semaines à un petit nombre de mois. Or, ultérieurement, dans le cas du VIH, les animaux ne semblent pas protégés (encore n'a-t-on pas mené assez systématiquement les expériences cruciales qui permettraient

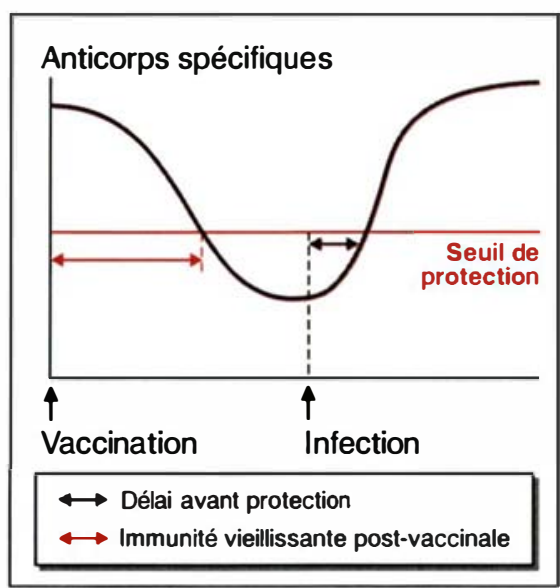

Figure 5. La mémoire immunitaire. Dans les semaines qui suivent la vaccination, le sujet est protégé du virus par les anticorps neutralisants et par des CTL. Très vite, cependant, le taux d'effecteurs diminue au-dessous du seuil d'efficacité. Un nouveau contact avec le virus (infection) déclenche une réaction anamnestique puissante. Avec le VIH, on n'a pu obtenir, jusqu'à présent, de protection vaccinale qu'au moment du pic vaccinal d'anticorps, vraisemblablement par réponse neutralisante. Ultérieurement, les animaux ne semblent pas protégés. de s'en assurer). Le problème essentiel paraît donc être d'induire par la vaccination des réponses anamnestiques puissantes et rapides des anticorps neutralisants et une réponse anamnestique également puissante et rapide des cellules $T$ tueuses, pour éliminer les premières cellules infectées, puisqu'un certain nombre de cellules seront nécessairement infectées chez les sujets qui s'infecteront quelques semaines ou quelques mois après la vaccination. Le VIH à cet égard, avec sa capacité d'infection chronique, maintenant du virus dans des sanctuaires, notamment macrophagiques, et transmettant cette infection à bas bruit pendant des années de cellule à cellule, est tout à fait différent des infections virales habituelles dans lesquelles le virus s'élimine de lui-même lorsque la réaction anticorps peut le contrôler (sauf éventuellement, mais non constamment, dans le cas de l'hépatite $B$ ). C'est pourquoi se pose à nous un problème immunologique que les spécialistes du vaccin n'ont jamais eu à résoudre et l'étude fondamentale de la mémoire immunitaire devient à l'évidence une des clés du vaccin contre le SIDA.

\section{Problèmes de la variabilité virale}

Le VIH-1 est doté d'une extraordinaire variabilité qui n'a jamais été rencontrée avec une autre famille virale. Plusieurs centaines de séquences de l'enveloppe sont connues, qui se regroupent en sept familles principales (A, B, C, D, E, F et O) auxquelles on tend à ajouter aujourd'hui deux autres familles $(G$ et $H)$. Le groupe $\mathrm{O}$, à lui seul, semble être hétérogène. Une variabilité semblable existe pour les autres protéines, quoique à un moindre degré. Fait essentiel, nous sommes actuellement incapables de rattacher définitivement cette variabilité à l'échappement aux anticorps car, pour des raisons techniques, les études de neutralisations croisées sont encore très insuffisantes. Les travaux menés dans divers pays devraient apporter des informations déterminantes à cet égard dans les deux ans qui viennent. Tout suggère cependant que les anticorps dirigés contre la boucle V3 de la gp120, qui est la cible principale des anticorps 
neutralisants, ne sont susceptibles de protéger que contre des virus proches de la souche immunisante. On sait, par exemple, que les sérums de malades ne donnent pas de neutralisations croisées entre les sous-familles B et E en Thaillande [14]. Chez les chimpanzés, par ailleurs, la protection n'a jusqu'ici été observée que contre des souches très voisines du virus vaccinant. Les sérums de sujets infectés peuvent pourtant révéler, dans certains cas, de larges réactions croisées. Celles-ci ne sont pas dues pour l'essentiel à des anti-V3 mais à des anticorps dirigés contre des sites conservés: certaines séquences de la protéine gp4l et surtout des zones de la protéine gp120 qui recoupent partiellement le site conformationnel complexe qui interagit avec la protéine CD4. Ces anticorps, qui finissent par exister en quantités importantes chez les sujets infectés, n'apparaissent cependant que tard au cours de l'infection et surtout ne sont pas induits jusqu'à présent par les préparations vaccinales.

Un gros effort doit donc être fait pour mieux comprendre les possibilités de réactions croisées entre boucles V3 différentes et déterminer en particulier si, d'une part, à l'intérieur d'une même famille de virus (la famille B qui circule majoritairement dans nos pays, par exemple) et, d'autre part, entre sous-familles virales, on peut véritablement obtenir des neutralisations croisées. Cela devrait nous indiquer, en cas de réponse positive, combien de séquences différentes devraient être incluses dans un éventuel vaccin. Si une dizaine ou une quinzaine de séquences pouvaient suffire, la réalisation d'un vaccin ne serait nullement insurmontable. Elle sera peu probable s'il en faut beaucoup plus. Restera à déterminer, de toute façon, comment on induit de bonnes réponses neutralisantes simultanées contre des isolats multiples et, en particulier, quelles préparations antigéniques et quels adjuvants il faudrait associer dès la stimulation primaire pour éviter la concentration ultérieure des anticorps sur l'antigène qui a été vu initialement, seul ou de façon prédominante, comme cela se passe chez les sujets infectés (phénomène dit du "péché originel antigénique»). La $\mathrm{m} / \mathrm{s} n^{\circ} 3$, vol. 11 , mars 95 préparation de multiples peptides, vraisemblablement de multiples protéines recombinantes, voire de multiples virus recombinants, sera peutêtre nécessaire pour parvenir à cette fin, ce qui ne fera pas un vaccin simple.

Si, en revanche, l'obstacle de la variabilité virale ne pouvait être surmonté de cette façon par des anti-V3 multiples, seules les séquences conservées des protéines portées par le virus resteraient des cibles possibles d'un vaccin. Ces séquences sont de trois ordres: les cibles de CTL, les épitopes conservés réagissant avec des anticorps neutralisants et des constituants non viraux inclus dans l'enveloppe virale.

1. Un certain nombre de séquences, qui sont les cibles des CTL, sont beaucoup plus nettement conservées que celles contre lesquelles sont dirigés les anticorps. C'est, en particulier, le cas dans certaines enzymes du virus, dans des protéines GAG et dans la protéine NEF qui a, en outre, l'avantage d'être exprimée très tôt au cours de l'infection et, par conséquent, de pouvoir constituer en principe une bonne cible de CTL. Les mutants d'échappement existent aussi pour les CTL $[15,16]$ et il est difficile, en outre, comme on l'a vu, de concevoir un vaccin qui serait fondé essentiellement sur l'induction de CTL. La difficulté est d'autant plus grande que les CTL ont une activité restreinte par les molécules HLA et que chaque sujet choisit de reconnaître dans un virus des épitopes différents, en fonction de ses propres molécules HLA. Une combinaison d'un grand nombre de séquences devrait donc être associée. Heureusement, l'association de multiples épitopes dans certaines zones virales ne rend pas nécessairement ce problème insoluble.

2. Il existe, par ailleurs, des séquences conservées sur l'enveloppe virale, dans la protéine gp120 ou dans la protéine gp4l qui donnent lieu à des anticorps neutralisants. Malheureusement, comme on l'a vu, la difficulté est d'obtenir une réponse contre de telles séquences chez les sujets vaccinés: jusqu'à présent les tentatives ont échoué. Il est à noter, par ailleurs, que beaucoup des séquences conservées contre lesquelles on peut obtenir des anticorps ne sont pas nécessairement intéressantes pour une vaccination, dans la mesure où beaucoup d'entres elles ne sont pas accessibles sur la protéine dans sa structure native et moins encore dans le multimère de gp120 qui constitue les spicules d'enveloppe. La recherche se poursuit dans ce domaine, notamment dans le but de provoquer des réponses fortes contre la structure conformationnelle de la protéine d'enveloppe qui interagit avec le récepteur cellulaire CD4, puisqu'elle est très conservée. Chez l'homme, elle induit des anticorps lors de l'infection mais assez tardivement, bien après les anti-V3. Chez les sujets vaccinés, les résultats paraissent médiocres jusqu'à présent, mais on peut peut-être espérer les améliorer en immunisant, par exemple, contre des complexes gp120/CD4 conservant la structure de ces épitopes [17] ou contre d'autres complexes ayant pour but de maintenir ou d'extérioriser la structure conformationnelle cible.

3. Sur le virus se trouvent des protéines d'origine cellulaire, en particulier des antigènes HLA-DR, des chaînes HLA de classe I et des molécules de $\beta 2$ microglobuline, dont plusieurs centaines peuvent exister à la surface du virion. On sait que des anticorps d'origine animale, dirigés contre ces structures, sont susceptibles de neutraliser le virus. On a même protégé des macaques contre un SIV poussé dans des cellules humaines grâce à la réponse contre ces molécules $\left(m / s n^{\circ} 9\right.$, vol. 7, p. 982) [18-20]. Ce sont surtout les réactions contre les molécules HLA-DR qui semblent en cause, et l'on sait que ces molécules sont également présentes dans l'enveloppe du VIH [21, $22]$. Une immunisation humaine allogénique, dirigée contre HLA-DR, a donc pu être envisagée par certains comme l'équivalent d'une vaccination anti-VIH, mais son application paraît peu vraisemblable. En effet, il faudrait que chaque individu soit immunisé contre de multiples HLA-DR, ce qui ne serait pas forcément sans conséquence, notamment pour d'éventuelles greffes futures. Surtout, du fait des parentés antigéniques entre spécificités HLA, on sait bien que l'on n'obtiendrait la plupart du temps une immunisation franche que contre certaines spécificités. Il 
persisterait des trous importants: les partenaires sexuels seraient donc dangereux ou non pour chaque sujet, en fonction de leur HLA ! En ce qui concerne la $\beta 2$-microglobuline, qui ne semble pas avoir été une molécule protectrice dans les expériences réalisées chez ce macaque, le problème est particulièrement difficile pour de multiples raisons: c'est une protéine du soi, massivement représentée dans l'organisme et qui n'induit habituellement pas d'anticorps chez l'homme, contrairement aux chaînes variables des molécules HLA de classe I ou aux deux chaînes des molécules de classe II, car elle est invariante. Rompre la tolérance immunitaire contre une telle protéine paraît difficile et, si l'on y parvenait, on peut imaginer que les anticorps produits seraient massivement absorbés dans l'organisme qui possède plusieurs milliers de molécules de $\beta 2$ microglobuline à la surface de la plupart des cellules, sans parler d'un certain taux de $\beta 2$ microglobuline circulante. En outre, si l'on pouvait vraiment franchir cet obstacle, on peut sérieusement se demander quel serait le risque des complexes immuns, d'une part, et de la réaction sérique et cellulaire de l'organisme contre la grande majorité de ses propres cellules, d'autre part. Les études de tolérance d'un vaccin de ce genre seraient particulièrement délicates, si même il était possible de le mettre au point. Des études fondamentales de ces phénomènes chez le macaque immunisé avec sa propre $\beta 2$ microglobuline (et non celle de l'homme évidemment) pourraient apporter des informations utiles dans ces domaines, mais l'utilisation vaccinale de cette approche paraît peu probable.

\section{Le problème des isolats sauvages}

Les anticorps obtenus, soit chez des sujets vaccinés, soit chez des animaux, neutralisent les souches immunisantes, qui sont toujours des souches de laboratoire, longuement passées en lignées cellulaires et habituellement de tropisme T. En revanche, ils ne neutralisent pas les isolats viraux sauvages humains et, d'une façon générale, les virus pro- faut noter, d'ailleurs, que ces isolats ont essentiellement un tropisme macrophagique. On ignore les raisons de cette différence de neutralisation. Elles doivent être cherchées d'abord dans la variabilité des isolats par rapport à la souche vaccinante, mais l'explication n'est pas suffisante. Il est clair que la différence est vraie aussi avec les molécules CD4 solubles qui neutralisent facilement les isolats entretenus en laboratoire et beaucoup plus difficilement, ou pas du tout, les isolats sauvages alors que leur cible n'est pas variable. Le problème peut être quantitatif, la résistance des isolats sauvages étant plus grande, mais il est vraisemblement aussi qualitatif: il est probable, en particulier, que la structure tridimensionnelle des épitopes présentés par les protéines recombinantes ou les peptides de synthèse utilisés comme vecteurs de vaccination ne corresponde pas exactement à la structure des mêmes épitopes de l'enveloppe sur le virus. On peut se demander alors si les vecteurs protéiques ou peptidiques qui sont les plus utilisés à ce jour sont réellement capables d'induire les réponses que l'on cherche. Les vaccins fondés sur de pseudo-particules virales [10-12] pourraient à cet égard prendre un intérêt particulier. Il est évident que la neutralisation des isolats sauvages est un prérequis à la mise en œuvre d'essais de protection chez l'homme, si l'on considère, comme cela est au moins vraisemblable, que les anticorps neutralisants ont un rôle important à jouer dans cette protection.

\section{Qu'avons-nous appris des modèles animaux?}

L'un des obstacles à la mise au point d'un vaccin contre le SIDA est la pauvreté des modèles animaux. Le chimpanzé s'infecte par le VIH-1 mais, en dehors même de la rareté et du coût de ces animaux, le modèle n'est pas idéal car l'infection n'est obtenue que par un très petit nombre de variants et habituellement pas par les isolats sauvages. Le chimpanzé ne développe pas de maladie et il ne semble pas s'établir chez lui la même relation entre le système macrophagique et le virus que celle qui existe chez l'homme. C'est pourtant notre seul modèle d'étude à long terme d'une infection par le VIH-1. La souris immunodéprimée SCID humanisée (SCID/hu) peut constituer un modèle complémentaire utile mais, là encore, il n'apparaît pas de maladie proprement dite, la variabilité de l'infection est grande d'un cas à l'autre et le suivi à long terme du système, dans la plupart des cas, impossible. L'infection du macaque par le virus VIH-2 est possible, mais le modèle n'est pas d'un maniement facile à large échelle, ne serait-ce qu'en raison de la variabilité des résultats. Le macaque infecté par un virus de singe, le SIV, constitue certainement un bon modèle avec, en particulier, une maladie apparaissant en quelques mois à un petit nombre d'années, tout à fait analogue au SIDA humain. Cependant, dans la mesure où les anticorps neutralisants ne sont pas véritablement représentatifs du modèle humain (la boucle V3, en particulier, n'est pas déterminante), la situation de ce modèle, bien que proche, n'est pas tout à fait identique immunologiquement à la situation humaine.

Tout ce que nous avons appris jusqu'à présent de ces modèles se résume à peu de chose. Pour le chimpanzé, nous savons qu'une protection peut être obtenue contre du virus libre ou contre des cellules infectées, liée vraisemblablement à l'apparition d'anticorps neutralisants. Elle dure relativement peu de temps si l'animal n'est pas restimulé (encore les études sont-elles limitées sur ce point) et elle n'est dirigée que contre la souche immunisante ou des souches très proches. Ces indications sont insuffisantes pour pouvoir progresser très au-delà dans le dessin d'un vaccin. Actuellement, le chimpanzé sert cependant à tenter d'établir des modèles d'infections par voies sexuelles qui pourraient mieux nous guider quant à l'étude de la maladie naturelle, car ce sont toujours des infections veineuses qui ont été utilisées jusqu'à maintenant.

Chez le macaque infecté par le SIV, on a essentiellement observé des échecs, aussi bien avec les vaccins recombinants vivants qu'avec les vaccins protéiques ou peptidiques et avec les vaccins tués. Les seules protections obtenues dans ce dernier cas étaient des artefacts: la protection était due à des anticorps dirigés contre des antigènes humains pré- 
sents dans les virus SIV qui avaient été eux-mêmes cultivés sur des cellules humaines avant de servir aux expériences de vaccination. Lorsque le virus est cultivé sur des cellules de macaques, ce qui est sa situation naturelle, les mêmes animaux ne sont pas protégés [18-20]. La protection par un virus vivant portant une délétion du gène $N E F$ a, en revanche, été observée [23]. Elle est très particulière car elle n'apparaît qu'après de nombreux mois d'infection et on peut se demander si elle est réellement d'ordre immunologique. Elle pourrait être liée à une interférence virale massive lorsque la réplication du virus vaccinant a été suffisante pour saturer les sites cellulaires. Quoi qu'il en soit, et pour les raisons déjà évoquées au début de cet article, la transposition de ce modèle à l'homme en terme de vaccin paraît des plus difficiles.

A l'avenir, les modèles animaux et, en particulier, le SIV, sont susceptibles au plan expérimental de nous aider de façon importante dans notre réflexion mais ils ne peuvent pas constituer, comme c'est le cas pour de nombreux autres vaccins, un modèle direct de protection contre le VIH et la maladie qu'il induit.

\section{Qu'a-t-on appris dans des essais} vaccinaux chez l'homme?

Tous étaient des essais de phase I (Tableau III). Tous avaient pour but de vérifier la tolérance du produit et la réaction immune qu'il induit. La plupart des essais ont été menés avec un seul vecteur. Les essais menés en France ont, cependant, systématiquement comporté l'association de plusieurs immunogènes avec l'idée d'induire des réponses immunitaires multiples, peu vraisemblables avec une gp120 seule, par exemple. De tous ces essais, il résulte que l'on peut induire, chez l'homme, essentiellement à l'aide de protéines recombinantes d'enveloppe, des anticorps neutralisants à des taux notables mais rapidement dégressifs. Ces anticorps neutralisent seulement les souches immunisantes ou des souches voisines, mais pas des souches de laboratoire de séquences relativement éloignées et, a fortioni, des isolats sauvages. On a été également capable d'induire des cellules $\mathrm{T}$ tueuses chez l'homme avec des recombinants vivants mais, jusqu'à présent, à des taux relativement modestes. On peut espérer que l'utilisation de recombinants com-

Tableau III

PRINCIPAUX TYPES D'ESSAIS VACCINAUX DE PHASE I MENÉS CHEZ L'HOMME JUSQU'EN 1994

\begin{tabular}{|c|c|}
\hline Immunogènes & Industriels concernés \\
\hline 1. Protéine: ENV & $\begin{array}{l}\text { Microgenesis/Wyeth-Ayerst } \\
\text { Immuno } \\
\text { Genentech } \\
\text { Chiron/Biocim/Ciba-Geigy }\end{array}$ \\
\hline 2. Protéine ENV + peptides V3 & Pasteur Mérieux s.v. \\
\hline $\begin{array}{l}\text { 3. Recombinants viraux } \\
\text { - vaccine } \\
\text { - canarypox }\end{array}$ & $\begin{array}{l}\text { Bristol Myers Squibb/Oncogene } \\
\text { Pasteur Mérieux s.v. }\end{array}$ \\
\hline $\begin{array}{l}\text { 4. Recombinants viraux + protéines } \\
\text { ou peptides } \\
\text { - vaccine }+ \text { gp } 160 \\
\text { - canarypox + gp } 160 \\
\text { - canarypox + peptides }\end{array}$ & $\begin{array}{l}\text { Bristol Myers Squibb/Oncogene } \\
\text { Pasteur Mérieux S.v. } \\
\text { Pasteur Mérieux s.v. }\end{array}$ \\
\hline 5. Peptides V3 sur microparticules & UBI \\
\hline 6. Peptides p17 & Viral Technology \\
\hline 7. Particules Ty/P24 & British Bio-Technology \\
\hline
\end{tabular}

$m / s n^{\circ} 3$, vol. 11, mars 95 plexes devrait améliorer la réponse à cet égard.

Les essais qui vont se dérouler maintenant devraient nous dire dans les deux à trois années qui viennent :

1. si nous pouvons induire une immunité muqueuse anti-VIH-1;

2. si nous sommes capables d'induire simultanément une réponse CTL et une réponse neutralisante fortes et prolongées ;

3. si nous savons neutraliser les isolats sauvages:

4. quelles combinaisons applicables à grande échelle permettent ces réponses multiples;

5. si nous sommes capables de passer outre à la variabilité, que ce soit par l'emploi de multiples boucles V3 ou, plus tard peut-être, par l'immunisation contre des séquences conservées.

\section{Quand des candidats vaccins pourront-ils être testés en phase III?}

La phase III, celle des essais de protection, n'est possible avec le VIH que sur de grands échantillons de populations très exposées. C'est en effet un virus à taux de transmission relativement faible et, sur toute autre population, des dizaines de milliers de volontaires, étudiés pendant des années risqueraient d'être nécessaires pour obtenir des données statistiquement significatives. La difficulté d'organiser des essais dans les pays du Nord, relativement peu touchés, est à cet égard considérable. Ce sont vraisemblablement les pays massivement touchés du tiers monde qui constitueront des sites d'essais. Ces essais soulèvent un problème éthique: les populations sur lesquelles ils devront être réalisés sont marquées par un risque élevé de contamination et ce risque est lié à leur comportement. La situation n'est pas la même que lors d'une vaccination contre une maladie virale épidémique classique. Dans celle-ci, la phase d'exposition à la contamination est courte et surtout l'échec du vaccin n'augmente pas le risque de contamination, si du moins il n'a pas induit d'anticorps facilitants $\left(m / s n^{\circ} 2\right.$, vol. 3, p. 109 et $n^{\circ} 8$, vol. 4, p. 526). Dans le cas du VIH, c'est chaque jour de leur vie que par leurs imprudences sexuelles les sujets peuvent se contaminer, et pas seule- 
ment pendant une période épidémique courte. Or, parce que certains sujets auront tendance à se croire protégés, l'expérience vaccinale comporte en elle-même un risque important d'induire un relâchement des comportements de prévention dont on sait à quel point ils sont difficiles à soutenir. Le risque est d'autant plus grand que ces essais devront être menés dans des pays peu développés et dans les tranches de populations les plus pauvres et les moins éduquées. Il n'est donc pas acceptable d'envisager ces essais, quelles que soient les mesures d'accompagnement que l'on prendra, sans avoir obtenu une garantie sérieuse quant aux chances d'efficacité. A titre d'exemple, des essais vaccinaux faits avec un virus préparé sur des souches occidentales (famille B) et réalisés dans des pays du tiers monde, asiatique (où prédominent les souches $\mathrm{E}$ ) ou africain (où prédomineront des souches $\mathrm{A}, \mathrm{C}$ ou D) ne seraient pas acceptables, à moins que nous ayons au moins acquis la certitude d'obtenir in vitro des protections croisées significatives.

Quels critères devrait-on réunir pour se considérer en droit de lancer des essais vaccinaux à grande échelle $(f i$ gure 6) ? Il est clair que l'absence d'un modèle animal satisfaisant gêne considérablement la prise de décision dans ce domaine. Même si le candidat vaccin aura pu être testé sur un certain nombre de chimpanzés avant le passage à l'homme, il restera difficile de tirer des conclusions définitives de ce modèle. C'est pourquoi on doit chercher à obtenir, dans des conditions expérimentales analogues à celles envisagées pour le vaccin humain, des protections contre le SIV chez le macaque. On peut se fonder surtout sur une série d'arguments immunologiques, obtenus chez l'homme lors d'essais de phase I/II, et qui rendent vraisemblables les chances de protection: (a) l'induction d'anticorps neutralisants actifs contre de multiples souches dont celles qui circulent dans la population testée, c'est-à-dire contre les isolats sauvages, pourrait être un argument décisif; (b) l'existence simultanée d'une franche réponse CTL serait un argument supplémentaire, mais probablement pas suffisant à lui seul; (c) celle d'une immunité muqueuse par des

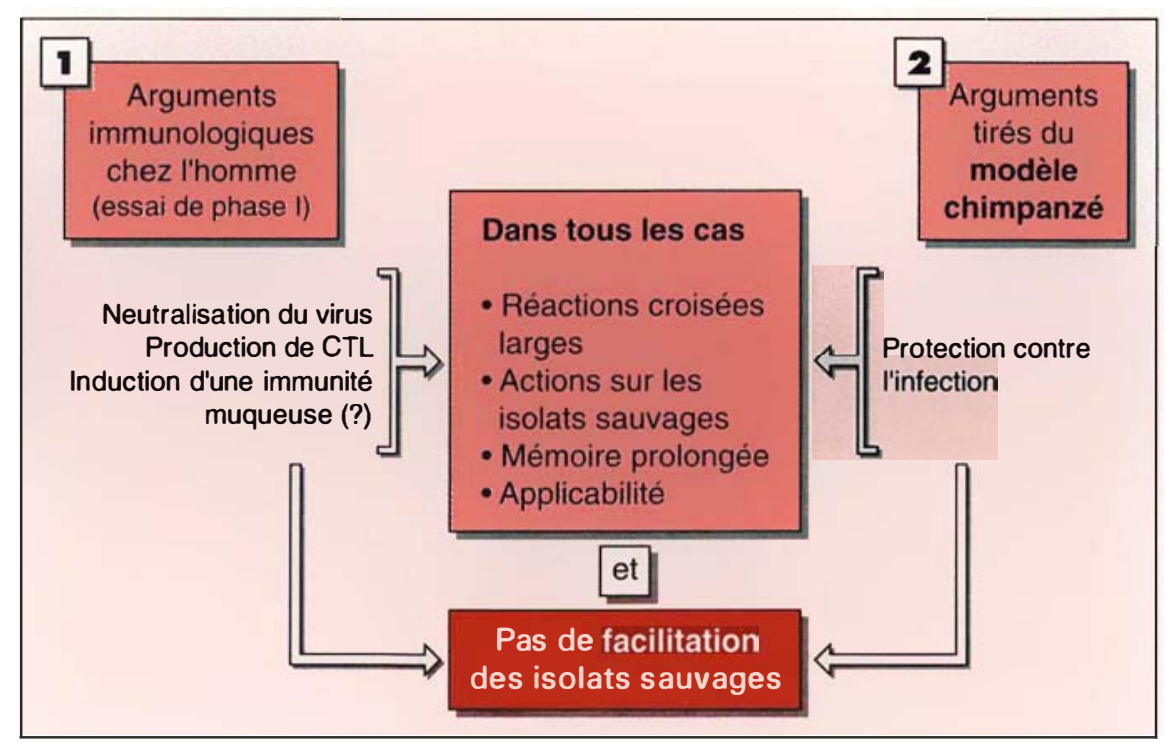

Figure 6. Préalables à des essais de phase III.

argument d'appoint; (d) en tout cas: celle d'une mémoire immunitaire satisfaisante est indispensable; (e) en outre, l'induction d'anticorps facilitants ne doit pas être négligée et il est essentiel de s'assurer que la vaccination n'en induit pas, non seulement contre le virus vaccinant, mais encore contre une série d'isolats sauvages. Il ne faut pas exclure, cependant, d'envisager des essais de phase III en l'absence de corrélats immunologiques clairs si au moins une protection prolongée et massive était obtenue contre de multiples isolats sauvages dans un modèle animal.

Il ne fait aucun doute que la prise de décisions sera difficile, d'autant plus, il faut le reconnaître, qu'aucun de ces arguments n'est en soi décisif et définitivement validé. Cependant, tant que nous n'aurons pas obtenu, dans les expériences de phase I/II, des résultats beaucoup plus significatifs que ceux observés jusqu'à maintenant, il ne sera pas logique, malgré toutes les pressions qui peuvent s'exercer, de passer en phase III. Quelles que soient ces pressions, l'éthique impose de retarder les essais de protection aussi longtemps qu'il sera nécessaire pour obtenir des critères raisonnables, au risque d'induire des sujets à s'exposer et se contaminer alors que les chances d'efficacité seraient très faibles. Il faudra aussi se rappeler qu'on ne pourra pas multiplier des expé- riences lourdes, longues, coûteuses et pour lesquelles il n'existe en fait que peu de terrains acceptables.

Il reste que nous ne savons pas en 1994 s'il sera possible de mettre au point un vaccin contre le SIDA, mais qu'une série de recherches et d'essais en phase I/II chez l'homme est cruciale pour déterminer, dans les deux à trois ans qui viennent, si les voies dont nous disposons vraiment en pratique peuvent y mener. Il n'est pas certain non plus que l'on puisse viser un vaccin protecteur contre tous les isolats et le rapport risque/efficacité de vaccins partiellement efficaces devra être évalué s'il en apparaît, pour les pays du Nord, d'une part, et pour le tiers monde massivement touché et peut-être moins accessible à la prévention classique, d'autre part. Il est à noter à cet égard que les modèles mathématiques suggèrent une certaine prudence dans l'utilisation des vaccins "partiels" dont on ne peut, semblet-il, espérer d'effets importants et qui ne permettraient probablement pas d'envisager un quelconque relâchement des attitudes classiques de prévention [24]. Il importe en fait de définir ce que l'on appelle "efficacité partielle "? Elle peut l'être en termes de pourcentage de sujets chez lesquels une protection est induite, ou en termes de degré de protection chez ces sujets (qui dépend du pourcentage des isolats contre lesquels le 
sujet est plus ou moins protégé, et de l'importance du risque résiduel pour ces mêmes isolats). La conjonction de ces deux éléments, auxquels il faut ajouter la durée de la protection, montre que, pour être efficace en terme d'éradication de l'épidémie, le taux de protection dans les populations très exposées devrait être en fait très élevé. Le coût de vaccins, quels qu'ils soient, risque par ailleurs d'être relativement élevé et, plutôt que d'imaginer, comme certains, la recherche de vaccins "à bas prix" pour le tiers monde, ce qui paraît illusoire et à tout le moins fort prématuré, il faut certainement dès maintenant envisager la prise en charge par les pays riches de la vaccination du reste du monde, si des vaccins sont un jour mis au point.

On voit mal ce qui, en l'absence de vaccin, pourrait mettre un terme à cette épidémie. Il ne faut pas oublier cependant trois notions: l'éradication d'un virus de ce type ne saurait être rapide, et elle implique le main- tien des attitudes classiques de prévention. En fait, nous savons bien qu'avec la diffusion d'un vaccin des modifications importantes des comportements sexuels dans le sens du relâchement des efforts de prévention sont à craindre, avec de possibles effets pervers aggravant l'épidémie si le vaccin n'est que partiellement efficace. Enfin, l'émergence de nouveaux variants est, à cet égard, un élément essentiel à prendre en considération. Tout cela implique une extrême prudence dans les décisions d'essais de phase III tant que nos bases scientifiques ne seront pas plus solides.

\section{Conclusion}

Malgré des protections temporaires contre certains variants obtenues chez le chimpanzé, nous sommes encore loin de la mise au point d'un vaccin contre le SIDA [25]. Les résultats des approches actuelles sont manifestement insuffisants et ne justi- fient pas le passage à la phase III des essais. Les années qui viennent devraient nous permettre cependant de répondre à quelques questions clés de ce problème. Celle, en particulier, de la possibilité ou non de protéger contre de multiples isolats, malgré la variabilité virale, et de le faire à relativement long terme. Par ailleurs, des approches nouvelles, tendant à utiliser comme cibles les séquences conservées de l'enveloppe, par exemple, ou à augmenter les réponses relayées par les CTL, à utiliser comme immunogènes des pseudoparticules virales conservant les structures naturelles du virus, ou encore à provoquer l'immunisation grâce à la présentation de ces structures par les cellules du sujet, après injection d'ADN viraux, sont, on peut l'espérer, susceptibles de modifier sensiblement les choses

\section{TIRÉS À PART}

J.P. Lévy.

\section{Summary}

Problems in vaccination against HIV

Vaccinations are currently used in human beings against a dozen of viruses which generally induce acute infections. The human immunodeficiency virus (HIV) is different from these viruses by multiple properties, which make uncertain the possibility to vaccine against AIDS. Among these differences, one of the most significant could be the fact that it would be hardly possible to produce a vaccine based on classical methods, including the use of killed or attenuated viruses. Ongoing experiments are done with recombinant viruses or bacteria, purified recombinant proteins, chemically synthesized peptides or viral pseudoparticles. The use of DNA vaccination could be of special interest. In all cases, we try to induce a triple antiviral immune response including neutralizing antibodies, cytotoxic T lymphocytes and a mucosal immune response. These responses must be measured against field isolates. It must be also assessed that facilitating antibodies are not induced by the vaccine and this must be tested against a panel of field isolates circulating in the population to be tested. Animal models have shown that it is possible to protect chimpanzees against the virus used to vaccinate or closely related variants. Nevertheless, this protection has been obtained for short periods of time and protection against sexual infections has not been demonstrated. In macaques infected by the SIV (a simian equivalent of HIV), protection was found only with attenuated virus and the results would be hardly applicable in human beings. Phase I clinical trials in human beings have tested for the most part recombinant envelope proteins and/or peptides as well as some recombinant viruses. Their preliminary results show that neutralizing antibodies can be induced in normal volunteers while at a relatively low level but without neutraliza- tion of field isolates. CTL have been also produced at relatively low levels. The mucosal immunity is practically unknown in these experiments. Some major questions remain to be solved before we could begin phase III trials. Among them, the possibility to vaccinate against multiple isolates despite the tremendous variability of the virus, as well as the possibility to induce long lasting protection or neutralization against field isolates, are the most important. Phase III trials must be probably delayed until we could obtain immunological argument suggesting we are able to induce a protection against multiple field isolates. Nevertheless, correlation between immunological parameters and protection remains uncertain and protection against multiple isolates in animal model could be also an argument to begin phase III trials which presently appear largely premature. 